\title{
Effect of inhaled 15-(s)-hydroxyeicosatetraenoic acid on tracheobronchial clearance in normal human airways
}

Christopher K W Lai, Riccardo Polosa, Demetri Pavia, Amir Hasani, John E Agnew, Stewart W Clarke, Stephen T Holgate
Immunopharmacology Group, Medicine I, Southampton General Hospital, Southampton SO9 4XY C K W Lai R Polosa $S$ T Holgate

Department of Thoracic Medicine, Royal Free Hospital and School of Medicine, London NW3 2QG D Pavia

A Hasani

J E Agnew

S W Clarke

Reprint requests to Dr Christopher Lai, c/o Department of Medicine, Chinese University of Hong Kong, Prince of Wales Hospital, Shatin, New Territories, Hong Kong Accepted 15 March 1991

\begin{abstract}
15-(s)-Hydroxyeicosatetraenoic acid (15HETE) is the predominant metabolite of arachidonic acid in normal and asthmatic human airways and a potent mucus secretagogue in canine and human airways. A study was carried out on the effect of inhaled 15-HETE on tracheobronchial clearance, measured for six hours by a radioaerosol technique, in 10 normal subjects. Subjects inhaled $80 \mathrm{nmol}$ 15-HETE or the diluent (sodium phosphate buffer) on two occasions at least two weeks apart in a double blind and randomised fashion ( 20 minutes after radioaerosol inhalation. Tracheobronchial clearance after inhaled 15-HETE was almost identical to that after placebo for all measurements up to six hours. It is concluded that 15HETE has no effect on tracheobronchial clearance in normal human airways and is unlikely to account for the impaired mucociliary clearance seen in asthma.
\end{abstract}

15-(s)-Hydroxyeicosatetraenoic acid (15HETE) is the predominant oxidative metabolite of arachidonic acid in both normal and asthmatic airways. ${ }^{1}$ Release of $15-$ HETE from asthmatic airways is greatly enhanced by allergen challenge in vitro and in vivo. ${ }^{12}$ When stimulated appropriately human eosinophils $^{3}$ and airway epithelial cells ${ }^{45}$ release 15-HETE as their major lipid product and this may be the source of its release in allergic reactions affecting airway mucosal surfaces, as in asthma. Despite overwhelming evidence for the generation of 15-HETE in asthma, the role of this eicosanoid is still undefined. In vitro 15-HETE is able to stimulate leukotriene synthesis by mast cells ${ }^{67}$ and this action may be responsible for the potentiating effect of 15-HETE on allergen induced early asthmatic response ${ }^{8}$ as this is largely a mast cell mediated event. We may plausibly speculate that the reduced mucociliary clearance seen during the early asthmatic response ${ }^{9}$ may be initiated by the substantial amount of 15-HETE generated in the airways after allergen stimulation. ${ }^{1}$ This reduction in mucociliary clearance is blocked by pretreatment with sodium cromoglycate ${ }^{10}$ or the leukotriene antagonist FPL-55712, suggesting that mediators released from mast cells, and in particular the leukotrienes, may have a role. Besides acting via the mast cell mediators, 15-HETE may also act directly to impair mucociliary clearance in asthma, as it has been shown to be a potent mucus secretagogue in canine airways in vivo and in human airways in vitro. ${ }^{112} \mathrm{We}$ therefore studied the effect of inhaled 15-HETE on mucociliary clearance in non-asthmatic subjects.

\section{Methods \\ SUBJECTS}

Ten healthy non-smokers with no history of asthma took part in the study (table 1). They took no medication and had been free from respiratory tract infections for at least four weeks before the study. Five subjects were atopic as defined by positive skinprick tests (weal response of more than $2 \mathrm{~mm}$ ) with two or more allergens-grass pollen, Dermatophagoides pteronyssinus, and cat dander (Bencard, Brentford, Middlesex). The study was approved by the Royal Free Hospital's ethical practices subcommittee, and written informed consent was obtained from each subject.

\section{MEASUREMENTS}

Forced expiratory volume in one second $\left(\right.$ FEV $\left._{1}\right)$ and forced vital capacity (FVC) were measured with a dry bellows spirometer (Vitalograph, Buckingham) 10 to 20 minutes before each radioaerosol inhalation. The highest value from three technically acceptable measurements was recorded. All readings were corrected for body temperature and ambient pressure.

Table 1 Characteristics of the subjects

\begin{tabular}{|c|c|c|c|c|c|}
\hline $\begin{array}{l}\text { Subject } \\
\text { No }\end{array}$ & Sex & $\begin{array}{l}\text { Age } \\
(y)\end{array}$ & Atopy & $\begin{array}{l}F E V_{1} \\
\text { (\% pred) }\end{array}$ & $\begin{array}{l}\text { Height } \\
(m)\end{array}$ \\
\hline 1 & $\mathbf{M}$ & 34 & - & 93 & 1.72 \\
\hline 2 & $\mathbf{F}$ & 26 & - & 133 & 1.68 \\
\hline 3 & $\mathbf{M}$ & 32 & + & 110 & 1.64 \\
\hline 4 & $\mathbf{M}$ & 27 & + & 130 & 1.77 \\
\hline 5 & $\mathbf{F}$ & 52 & - & 104 & 1.66 \\
\hline 6 & $\mathbf{M}$ & 27 & + & 89 & 1.68 \\
\hline 7 & $\mathbf{M}$ & 33 & - & 111 & 1.80 \\
\hline 8 & $\mathbf{M}$ & 31 & + & 108 & 1.74 \\
\hline 9 & $\mathbf{M}$ & 24 & - & 100 & 1.74 \\
\hline 10 & $\mathbf{M}$ & 33 & + & 98 & 1.66 \\
\hline Mean & & 32 & & 108 & $1 \cdot 71$ \\
\hline SE & & 2.5 & & $4 \cdot 6$ & 0.02 \\
\hline
\end{tabular}


Tracheobronchial clearance was measured by a non-invasive radioisotopic method. ${ }^{13}$ Five micron polystyrene particles were firmly tagged with the gamma emitting radionuclide technetium-99m $\left(t^{1 / 2}=\right.$ six hours $)$ and inhaled via the mouth under strictly controlled conditions. The initial topographical distribution of the radioaerosol within the lungs was monitored with a gamma camera (International General Electric, Berkshire) linked to a computer (Nodecrest, Byfleet). Posterior views were obtained to derive a penetration index for the ${ }^{99 \mathrm{~m}} \mathrm{Tc}$ labelled particles (ratio of counts recorded over peripheral lung to those recorded over central lung). ${ }^{14}$ This index estimates the degree of penetration into the lungs of the radioaerosol relative to that of labelled krypton gas $\left({ }^{81 \mathrm{~m}} \mathrm{Kr} ; \mathrm{t}^{1 / 2}=13\right.$ seconds), which was subsequently inhaled.

Radioaerosol clearance was monitored with two suitably collimated scintillation counters, axially opposed anteroposteriorly over the midsternum. An immediate radioaerosol count was made to ascertain the initial lung burden. Thereafter counts were made at half hour intervals for six hours and a final measurement at 24 hours to estimate the amount of radioaerosol in non-ciliated airways - that is, alveolar deposition. After correction for the natural decay of the radioisotope and background radioactivity all counts were expressed as a percentage of the initial count to allow for differences in initial lung burden. Alveolar deposition for each subject was determined as the percentage of the initial lung burden remaining in the lungs at 24 hours and was subtracted from the whole lung clearance curve to give a tracheobronchial clearance curve. Coughs were recorded and sputum collected and weighed for six hours after aerosol inhalation. The tracheobronchial clearance curve was corrected for productive coughs. ${ }^{15}$

\section{DRUG ADMINISTRATION}

Aliquots of 15-(s)-hydroxyeicosatetraenoic acid (15-HETE) (Chiral Organics, Reading) dissolved in $100 \%$ ethanol at a concentration of $2.47 \mathrm{mg} / \mathrm{ml}$ and of $100 \%$ ethanol alone (placebo) were stored at $-20^{\circ} \mathrm{C}$ under nitrogen until they were used. Each aliquot was diluted with isotonic $(0.15 \mathrm{M})$ sodium phosphate buffer, $\mathrm{pH} 7.4$ immediately before use to produce a $2 \mathrm{ml}$ solution containing $10 \%$ alcohol and either $1 \mathrm{mM}$ 15-HETE or placebo. Each solution was stored at $-4^{\circ} \mathrm{C}$ until 20 minutes before inhalation, when it was left at room temperature. Both the 15-HETE and placebo solutions were administered as aerosols generated from a starting volume of $2.0 \mathrm{ml}$ in a disposable Inspiron Min-Neb nebuliser (C R Bard International, Sunderland), connected to a dosimeter driven by compressed air at a pressure of $25 \mathrm{lb} / \mathrm{in}^{2}(138 \mathrm{kPa})$. Subjects wearing a nose clip were instructed to take five consecutive breaths from functional residual capacity to total lung capacity via a mouthpiece. The dosimeter setting was adjusted so that $80 \mu \mathrm{l}$ of aerosol was generated, corresponding to $80 \mathrm{nmol} 15$-HETE (mass median particle diameter $4.7 \mu \mathrm{m}$ ) leaving the nebuliser.

\section{STUDY DESIGN}

Each subject was studied on two occasions separated by at least two weeks. In a randomised and double blind manner subjects inhaled on each occasion either a single dose of $80 \mathrm{nmol} \mathrm{15-HETE} \mathrm{or} \mathrm{vehicle} \mathrm{placebo} 20$ minutes after inhalation of the radioaerosol. Regular whole lung counts were measured as described above and a tracheobronchial clearance curve was plotted for each subject on each occasion.

\section{DATA ANALYSIS}

All figures are means (with standard errors in parentheses) unless otherwise stated, and the $\mathrm{p}<0.05$ level was accepted as significant. Baseline values of $F E V_{1}$ and FVC on the two study days were analysed by Student's $t$ test. Penetration indices, alveolar depositions, and inspiratory flow rates on the two days were compared by Wilcoxon signed rank tests. The area under the tracheobronchial ${ }^{99 \mathrm{~m}} \mathrm{TC}$ polystyrene particle retention curves (AUC) was calculated by trapezoid integration between time points 0 and six hours $\left(\mathrm{AUC}_{0-6}{ }_{\mathrm{h}}\right)$ and between time points 0 and three hours $\left(\mathrm{AUC}_{0-3 \mathrm{~h}}\right)$, and compared by Wilcoxon signed rank tests.

\section{Results}

Baseline pulmonary function, inspiratory flow rates, penetration indices, and alveolar depositions did not differ significantly on the two study days (table 2).

Only one subject (No 6) had a productive cough after inhaling placebo and the tracheobronchial retention curve was corrected as described previously. ${ }^{15}$ Tracheobronchial clearance after inhalation of 15-HETE was almost identical to that after placebo whether AUC was calculated for the first three hours (138 (8.6) $v 135(11 \cdot 1) \% \mathrm{~h}, \mathrm{NS})$ or for the whole six hours $(173(16.0)$ v $173(19.0) \% \mathrm{~h}$, NS; Figure).

\section{Discussion}

In this study inhaled 15-HETE had no measurable effect on tracheobronchial clearance in normal subjects. With the nebulisation procedure used, about $10 \%$ of the dose administered to the mouth - that is, $8 \mathrm{nmol}$ should have been delivered to the airways of our subjects. This is more than 10 times the dose administered to normal mongrel dogs by Johnson et al, who reported mucus hypersecretion and inflammatory changes in the airways of

Table 2 Mean (SE) baseline spirometric values, inspiratory flow rates, penetration indices, and alveolar deposition in the 10 subjects on the two study days *

\begin{tabular}{lcc}
\hline & $15-$ HETE & Placebo \\
\hline FEV $(1)$ & $4.0(0 \cdot 3)$ & $4 \cdot 0(0.3)$ \\
Forced vital capacity (1) & $4.7(0 \cdot 3)$ & $4 \cdot 8(0 \cdot 3)$ \\
Inspiratory flow (1/min) & $33.9(3.9)$ & $39.7(6.2)$ \\
Penetration index & $0.56(0.06)$ & $0.55(0.05)$ \\
Alveolar deposition (\%) & $41.5(4 \cdot 5)$ & $43 \cdot 1(4 \cdot 8)$ \\
\hline
\end{tabular}

*None of the differences is significant.

15-HETE-15- $(s)$-hydroxyeicosatetraenoic acid 
$\%$ of initial

tracheobronchial

deposition

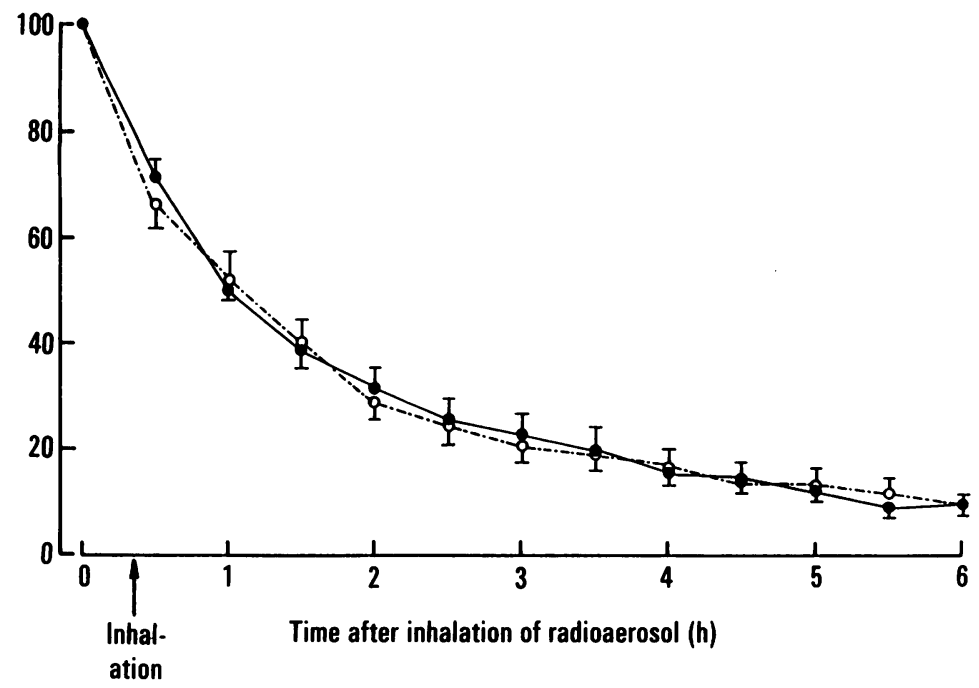

Mean tracheobronchial retention curves for 10 normal subjects after inhalation of $15-$

(s)-hydroxyeicosatetraenoic acid (15-HETE:solid circles) and placebo (open circles).

these animals. ${ }^{11}$ The biological activity of 15-HETE used in this study has been confirmed in our previous experiments, in which a similar inhaled dose delivered by an identical nebulisation system reduced bronchial responsiveness in normal and asthmatic subjects ${ }^{16}$ and augmented the early asthmatic response to inhaled allergen in patients with atopic asthma. ${ }^{8}$ Our failure to show any change in mucociliary clearance in these normal subjects is therefore unlikely to be due to an inadequate dose of inhaled 15-HETE and thus indicates that 15-HETE does not affect mucociliary clearance in normal subjects. Our results do not, however, exclude the possibility that 15HETE has an effect on asthmatic airways. Histamine, for example, causes greater stimulation of mucociliary transport in asthmatic than in normal airways. ${ }^{17} 18$

The tracheobronchial retention curves in our subjects closely resemble those reported in normal subjects, ${ }^{19}$ so the low concentration of alcohol in the vehicle solution is unlikely to have altered clearance and thus masked an effect of 15-HETE on the airway. The technique we used to measure tracheobronchial clearance is a well verified method for studying the effects of pharmacological agents in healthy subjects and patients with lung diseases. ${ }^{1720}$ It is highly repeatable, with an intersubject coefficient of variation for healthy non-smokers of $13 \%$ and an intrasubject coefficient of half this value. ${ }^{19}$ The power of our study had a $90 \%$ chance of detecting a $15 \%$ change in tracheobronchial clearance, quantified as area under the tracheobronchial retention curve, at the $5 \%$ level of significance. Thus our observation is unlikely to represent a type II error.

Given the profound degree of mucosal inflammation and mucus hypersecretion reported in normal dogs after inhalation of 15HETE, " we were surprised that 15-HETE had no effect on mucociliary clearance in normal subjects. We have shown that 15-HETE reduces rather than enhances bronchial hyperresponsiveness in normal and asthmatic subjects. ${ }^{16}$ These apparently contrasting effects on canine and human airways probably reflect a species difference in the biological function of this mediator.

Thus inhaled 15-HETE had no effect on tracheobronchial clearance in normal subjects. This result, with our earlier findings that 15HETE reduces human airways responsiveness in both normal and asthmatic subjects ${ }^{16}$ and has no effect on the allergen induced late asthmatic response ${ }^{8}$ suggests that this mediator, though present in great quantity in the asthmatic airways, is unlikely to be directly responsible for the inflammatory changes seen in this disorder.

We thank Ms $\mathrm{H}$ Yeung for typing the manuscript. This work was supported by the National Asthma Campaign, UK.

1 Murray JJ, Tonnel AB, Brash AR, Roberts LJ, Cosset $P$, Worknan R, Capron A, Oates JA. Release of prostaglandin $\mathrm{D}_{2}$ into human airways during acute antigen challenge. N Engl J Med 1986;315:800-4.

2 Dahlen SE, Hansson G, Hedqvist P, Bjork T, Granstrom E, Dahlen $B$. Allergen challenge of lung tissue from asthmatics elicits bronchial contraction that correlates with the release of leukotrienes $\mathrm{C}_{4}, \mathrm{D}_{4}$ and $\mathrm{E}_{4}$. Proc Natl Acad Sci USA 1983;80:1712-6.

3 Turk J, Mass RL, Brash AR, Roberts II LJ, Oates JA. Arachidonic acid 15-lipoxygenase products from human eosinophils. J Biol Chem 1982;257:7068-76.

4 Hunter JA, Finkbeiner WE, Nadel JA, Goetzl EJ, Holtzman MJ. Predominant generation of 15-lipoxygenase metabolites of arachidonic acid by epithelial cells from human trachea. Proc Natl Acad Sci USA 1985;82:4633-7.

5 Salari H, Chan-Yeung $M$. Release of 15-hydroxyeicosatetraenoic acid (15-HETE) and prostaglandin E2 (PGE2) by cultured human bronchial epithelial cells. $\mathrm{Am}$ J Respir Cell Mol Biol 1989;1:245-50.

6 Vanderhoek JY, Tare NS, Bailey JM, Goldstein AL, Pluznik DH. New role for 15-hydroxyeicosatetraenoic acid. Activator of leukotriene biosynthesis in PT -18 mast/basophil cells. J Biol Chem 1982;257:12191-5.

7 Goetzl EJ, Phillips MJ, Gold WM. Stimulus specificity of the generation of leukotrienes by dog mastocytoma cells. J Exp Med 1983;158:731-7.

8 Lai CKW, Polosa R, Holgate ST. Effect of 15-HETE on allergen-induced asthmatic responses. Am Rev Respir Dis 1990;141:1423-7.

9 Ahmed T, Greenblatt DW, Birch S, Marchette B, Wanner A. Abnormal mucociliary transport in allergic patients with antigen-induced bronchospasm: role of slow reacting with antigen-induced of anaphylaxis. Am Rev Respir Dis 1981; 124:110-4.

10 Mezey RJ, Cohn MA, Fernandez RJ, Januszkiewicz AJ, Wanner A. Mucociliary transport in allergic patients with antigen-induced bronchospasm. Am Rev Respir Dis 1978;118:677-84.

11 Johnson HG, McNee ML, Sun FF. 15-hydroxyeicosatetraenoic acid is a potent inflammatory mediator and agonist of canine tracheal mucus secretion. Am Rev Respir Dis 1985;131:917-22.

12 Marom Z, Shelhamer JH, Sun F, Kaliner M. Human airway monohydroxyeicosatetraenoic acid generation and mucus release. J Clin Invest 1983;72:122-7.

13 Pavia D, Sutton PP, Agnew JE, Lopez-Vidriero MT, Newman SP, Clarke SW. Measurement of bronchial mucociliary clearance. Eur $J$ Respir Dis 1983;64(suppl 127):41-56.

14 Agnew JE, Pavia D, Clarke SW. Airways penetration of inhaled radioaerosol: an index to small airways functions? Eur J Respir Dis 1981;62:239-55.

15 Fazio F, Lafortuna C. Effect of inhaled salbutamol on mucociliary clearance in patients with chronic bronchitis. Chest 1981;80(suppl):827-30.

16 Lai CKW, Phillips GD, Jenkins JR, Holgate ST. The effect of inhaled 15-(s)-hydroxyeicosatetraenoic acid (15HETE) on airway calibre and non-specific responsiveness in normal and asthmatic human airways. Eur Respir 1990;3:38-45.

17 Mussatto DJ, Garrard GZ, Lourenco RV. The effect of inhaled histamine on human tracheal mucus velocity and bronchial mucociliary clearance. Am Rev Respir Dis 1988;138:775-9.

18 Garrard CS, Mussatto DJ, Lourenco RV. Lung mucociliary transport in asymptomatic asthma: Effects of inhaled histamine. J Lab Clin Med 1989;113:190-5.

19 Del Donno M, Pavia D, Agnew JE, Lopez-Vidriero MT, Clarke SW. Variability and reproducibility in the measurement of tracheobronchial clearance in healthy subjects and patients with different obstructive lung diseases. Eur Respir J 1988;1:613-20.

20 Pavia D. Lung mucociliary clearance. In: Clarke SW, Pavia $\mathrm{D}$, eds. Aerosols and the lungs: clinical and experimental aspects. London: Butterworths, 1984:127-55. 